\title{
Pelatihan Manajemen Bengkel/Laboratorium Bagi Guru Mata Pelajaran Praktik di SMK Wilayah Kabupaten Pandeglang
}

\author{
Iik Nurulpaik ${ }^{1}$, Hasbullah ${ }^{2}$, Wawan Purmana ${ }^{3}$, Neris Peri Ardiansyah ${ }^{4}$ \\ Departemen Administrasi Pendidikan ${ }^{1}$, Departemen Pendidikan Teknik Elektro ${ }^{2,3,4}$ \\ Universitas Pendidikan Indonesia \\ Jalan Setiabudhi No. 229, Bandung \\ iik.nurulpaik@upi.edu ${ }^{1}, \underline{\text { hasbullah-elektro@upi.edu }}^{2}$, wawan_purnama@upi.edu ${ }^{3}$, $\underline{\text { nerisperia@upi.edu }}^{4}$
}

\begin{abstract}
Abstrak
Manajemen bengkel/laboratorium di Sekolah Menengah Kejuruan secara fungsinya belum dimanfaatkan secara maksimal, hanya terpaku sebatas penggunaan tempat praktikum siswa dan belum banyak dimanfaatkan oleh para pengelola dalam meningkatkan kulitas bengkel/laboratorium di sekolah. Manajemen fasilitas bengkel/laboratorium sangat penting dalam peningkatan kulitas guru dan siswa dalam memenuhi mutu pembelajaran dan hasil dari kulitas pembelajaran guna meningkatkan kualitas lulusan. Sekolah Menengah Kejuruan pada dasarnya tidak hanya diperuntukkan untuk memahami penguasaan teori saja, namun harus juga memiliki kompetensi teori dan praktik dalam memenuhi kriteria unjuk kerja. Dengan demikian guru memiliki peranan sangat penting dalam penguasaan dan pengeloaan bengkel. Pelatihan Manajemen Bengkel/Laboratorium Bagi Guru Mata Pelajaran Praktik di SMK Wilayah Kabupaten Pandeglang dilakukan untuk meningkatkan manajemen guru dalam melakukan pengelolaan fasilitas bengkel/laboratorium di SMK.

Kata kunci :
\end{abstract}

Manajemen Bengkel, Mata Pelajaran Praktik, SMK.

\begin{abstract}
The function of the workshop/laboratory management in Vocational High Schools has not been fully utilized, it is only limited to the use of student practicum places and has not been widely used by managers in improving the quality of workshops/laboratories in schools. The management of workshop/laboratory facilities is very important in improving the quality of teachers and students in meeting the quality of learning and the results of the quality of learning in order to improve the quality of graduates. Vocational High Schools are basically not only intended to
\end{abstract}

understand theoretical mastery but must also have theoretical and practical competence in meeting performance criteria. Thus the teacher has a very important role in mastering and managing the workshop. Workshop/Laboratory Management Training for Practical Subject Teachers at SMK Pandeglang Regency is carried out to improve teacher management in managing workshop/laboratory facilities at SMK.

Keywords :

Workshop Management, Practice Subject, SMK.

\section{Pendahuluan}

Pendidikan kejuruan memiliki karakteristik yang berbeda dengan pendidikan umum ditinjau dari kriteria pendidikan, substansi pelajaran, dan lulusannya. Kriteria yang harus dimiliki oleh pendidikan kejuruan menurut Finch \& Crunkilton (1984) dan Singh \& Sudarshan (2015) adalah: (1) orientasi pada kinerja individu dalam dunia kerja; (2) justifikasi khusus pada kebutuhan nyata di lapangan; (3) fokus kurikulum pada aspek-aspek psikomotorik, afektif, dan kognitif; (4) kepekaan terhadap dunia kerja; dan (5) memerlukan sarana dan prasarana yang memadai, dan adanya dukungan masyarakat. Menurut Miller (1985:51) pendidikan kejuruan dirancang sebagai hubungan antara sekolah dengan pekerjaan, asumsi yang ada bahwa orang-orang yang disiapkan melalui pendidikan kejuruan akan menemukan pekerjaan dan bahwa ini bisa terjadi karena persyaratan bagian dari pendidikan tersebut berlangsung dalam suasana produktif dan praktis. Pendidikan Menengah kejuruan mempunyai tujuan yang terfokus pada: persiapan untuk masuk kerja,

Iik Nurulpaik, Hasbullah, Wawan Purmana, Neris Peri Ardiansyah 
pemilihan karir, dan mengembangkan kompetensi tertentu sesuai bidang keahliannya (Billett, 2011; Rivai \& Sagala, 2010).

Mengingat tujuan dan pentingnya peran pendidikan kejuruan sebagaimana disebutkan oleh para pakar tersebut, maka peran bengkel pada sekolah menengah kejuruan (SMK) menjadi kebutuhan dan sarana yang harus ada untuk fasilitas praktik dalam penyiapan tenaga terampil di SMK. Bengkel/laboratorium di SMK merupakan sarana belajar untuk mensimulasikan pekerjaan sebagaimana kegiatan yang dilakukan oleh karyawan di industri (Yoto, 2015). Intitusi SMK di wilayah Kabupaten Pandeglang saat ini belum semuanya menerapkan penggunaan sistem manajemen bengkel yang terstandar pada kegiatan belajar mengajarnya mengingat keterbatasan sarana dan prasarana yang ada. Di sisi lain, bagi yang sudah menerapkan model sistem manajemen bengkel dalam pembelajaran, masih belum didukung dengan kemampuan dan keterampilan guru dalam penerapan di laboratorium atau bengkel agar terjaga kondisi fasilitas pendukung yang dapat membuat pembelajaran lebih tertata dan tercatat dalam administrasi kelengkapan bengkel, antara lain penggunaan fasilitas peralatan, bahan dan perlengkapan pendukung keselamatan dan kesehatan kerja.

Penelitian yang dilakukan Kustono, dkk Tahun 2008 ditemukan bahwa para guru SMK memerlukan ketrampilan manajemen bengkel untuk pembelajaran di SMK serta memerlukan pelatihan manajemen untuk mengatasi kendala-kendala yang terjadi di sekolah. Berdasarkan hasil observasi dan informasi masing-masing ketua bengkel/laboratorium SMK, diketahui bahwa bengkel/laboratorium sangat riskan terhadap bahaya kecelakaan kerja maupun kebakaran; sebab setiap kegiatan praktikum siswa akan menggunakan sarana yang ada disemua bengkel/ laboratorium dan terpakai secara maksimal serta selalu menggunakan aliran listrik yang berbahaya dengan sengatan listrik, utamanya praktikum otomotif selalu berhubungan dengan bahan bakar yang mudah terbakar dan gas buang merupakan gas racun bagi kesehatan, serta praktikum gas karbit bersinggungan dengan gas bertekanan tinggi yang mudah meledak, juga laboratorium memasak untuk siswa tata boga selalu berhubungan dengan api yang bersumber dari tabung elpiji yang semuanya sangat mudah meledak dan terbakar (flameable).

\section{KAJIAN LITERATUR}

Terry (1974:4) menyatakan bahwa proses manajemen tercermin pada gambar berikut:

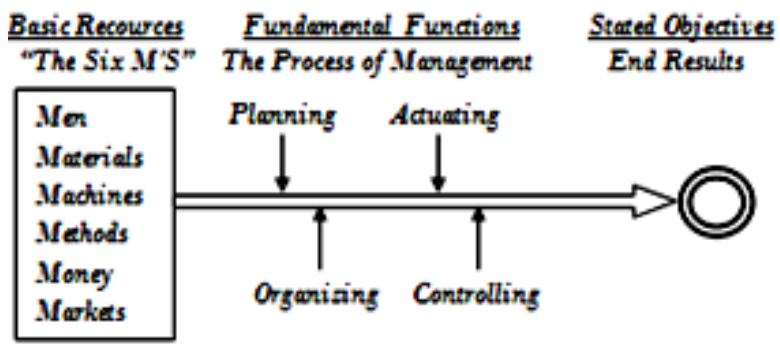

Gambar 1. Proses Manajemen

Manajemen merupakan suatu proses yang terdiri dari perencanaan (planning), pengorganisasian (organizing), pelaksanaan (actuating), dan pengawasan (controlling) untuk mencapai tujuan yang telah ditetapkan.

Pembelajaran di SMK terdiri dari dua jenis yaitu pembelajaran teori dan pembelajaran praktik. Pembelajaran teori diselenggarakan di ruang kelas sedangkan pembelajaran praktik diselenggarakan di bengkel praktik. Aurigemma, dkk (2013: 138) mengatakan bahwa: "if we can better understand how knowledge and skills are deployed in realworld engineering problem solving, we can better identify design principles to assist us in developing educational models that achieve fidelity between the two sites of the classroom and the work place whether it be a lab or industry". Pengetahuan dan keterampilan teknik lebih mudah dipahami dengan mengembangkan model pendidikan yang memadukan antara dua lokasi yaitu kelas dan tempat kerja baik itu bengkel praktik atau industri.

Rochadi (2011: 2-3) menyampaikan bahwa bengkel sekolah berfungsi sebagai tempat untuk alih kompetensi (transfering competense). Proses alih kompetensi dapat digambarkan sebagai berikut:

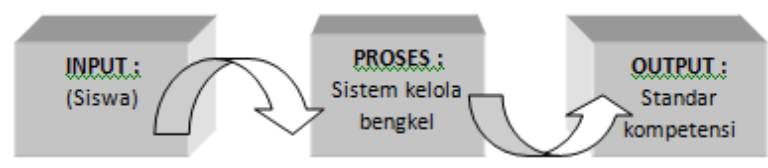

Gambar 2. Fungsi Bengkel Sekolah

(1) siswa sebagai input merupakan pelanggan yang harus dilayani sedemikian rupa sehingga apa yang menjadi harapan memperoleh kompetensi dari

Iik Nurulpaik, Hasbullah, Wawan Purmana, Neris Peri Ardiansyah

Jurnal Ilmiah Teknologi Informasi Terapan

Volume 7, No 1, 15 Desember 2020 
bidangnya dapat terpenuhi; (2) untuk dapat memperoleh kompetensi yang diharapkan, siswa dikembangkan di bengkel sekolah. Keberhasilan alih kompetensi siswa sangat ditentukan oleh bagaimana cara pengelolaan bengkel sekolah; (3) sasaran akhir dari pengembangan siswa adalah untuk mencapai kompetensi yaitu terdiri dari: keilmuan (knowledge), keterampilan (skills), maupun mental kepribadian (attitude). Sedemikian pentingnya peranan bengkel praktik yang digunakan sebagai tempat alih kompetensi (transfering competense), maka fasilitas bengkel praktik harus dikelola dengan baik dalam rangka pengembangan siswa untuk mencapai kompetensi yang diharapkan.

Sekolah Menengah Kejuruan (SMK) Bidang Teknologi dan Rekayasa memiliki beberapa Bengkel/laboratorium antara lain: Bengkel/laboratorium mesin produksi, Bengkel/laboratorium pengecoran logam, Bengkel/laboratorium pengelasan, laboratorium komputer, Bengkel/laboratorium mesin otomotif, Bengkel/laboratorium kerja kayu, laboratorium pengujian logam, laboratorium elektro, laboratorium elektronika, Bengkel/Laboratorium kerja bangku, dan lain sebagainya.

\section{METODE}

Metode dan tahapan yang digunakan dalam kegiatan Pelatihan Manajemen Bengkel/Laboratorium Bagi Guru Mata Pelajaran Praktik di SMK Wilayah Kabupaten Pandeglang dapat dijelaskan pada gambar 3 berikut.

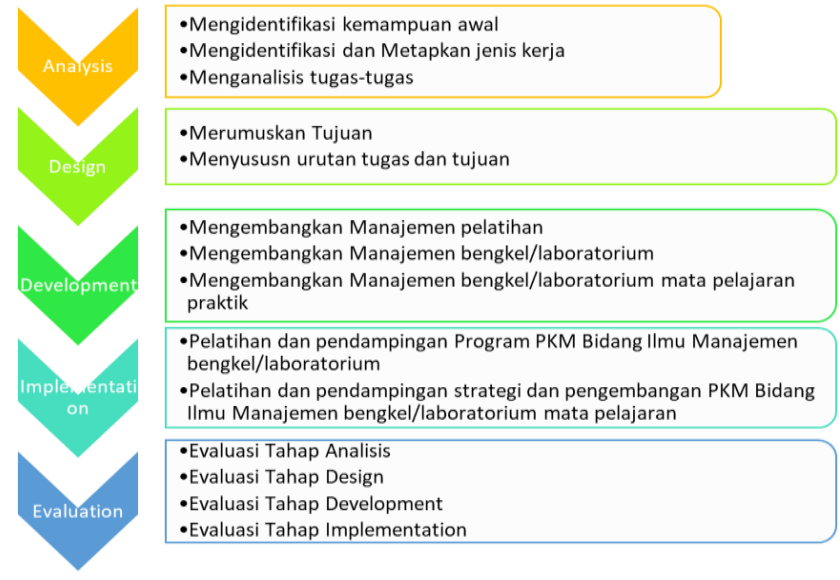

Gambar 3. Metode Kegiatan Pengembangan PKM Bidang Ilmu 2020
Secara umum tahapan kegiatan program pengabdian kepada masyarakat berbasis kepakaran bidang ilmu ini meliputi: perencanaan, pelaksanaan, dan evaluasi program.

a. Tahap Perencanaan: Need Assesstment (NA), studi pendahuluan oleh tim PKM Bidang Ilmu ini telah teridentifikasi bahwa problem yang dihadapi oleh Guru mata pelajaran Praktikum dalam mengembangkan menajemen bengkel/laboratorium smk di bidang mata pelajaran praktik masih belum dan sosialisasi tentang bagaimana memanfaatkan keahlian/ didiplin ilmu yang dimilikinya untuk manajemen bekel/laboratorium pada mata pelajaran praktikum. Disamping itu guru mata pelajaran praktik di SMK masih kurang melakukan manajemen pada pembelajaran praktik berdasarkan fasilitas yang telah tersedia.

b. Tahap Pelaksanaan: adapun kegiatan utama yang dilaksanakan pada tahapan pelaksanaan atau implementasi ini meliputi antara lain: (1) Penguatan sosialisasi dan komunikasi kepada para guru SMK, (2) Pelatihan manajemen bengkel/laboratorium bagi guru mata pelajaran praktik di SMK (3) Pengorganisasian bengkel/laboratorium dengan pembelajaran praktik (4) Penguatan dan pendampingan kegiatan dalam upaya menjaga kesinambungan program.

c. Tahap Evaluasi: tim pelaksana PKM Bidang Ilmu dari LPPM UPI bersama tim peneliti melakukan pengawasan langsung di lapangan terkait dengan progress report program dalam melaksanakan kegiatan pengabdian kepada masyarakat dengan menjadikan indikator input, proses dan output. Indikator proses adalah sejauh mana guru mata pelajaran praktik mampu mengembangkan kegiatan dalam program dan target-taget kerja yang akan dicapai bersama pemegang kebijakan atau kelompok sasaran. Indikator output adalah sejauhmana kinerja guru bisa memahami dan menerapkan manajemen bengkel/laboratorium di mata pelajaran praktik untuk mencapai standar kompetensi lulusan serta manfaatnya bagi dunia SMK dalam memanfaatkan dan melakukan efisiensi penggunaan bengkel/laboratorium di SMK. Diamping itu terwujudnya tujuan PKM yakni mendorong efisiensi bengkel/laboratorium di SMK di wilayah kabupaten Padeglang guna mencapai standar kompetensi lulusan guna mencapai peningkatan

Iik Nurulpaik, Hasbullah, Wawan Purmana, Neris Peri Ardiansyah

Jurnal Ilmiah Teknologi Informasi Terapan

Volume 7, No 1, 15 Desember 2020 
kulitas SDM dalam pemenuhan tuntutan lapangan kerja di dunia usaha dan dunia Industri.

\section{HASIL DAN PEMBAHASAN}

PKM Bidang Ilmu melakukan pembinaan terhadap peserta atau guru SMK yang mengikuti kegiatan Pelatihan Manajemen bengkel/laboratorium yang mana setiap peserta berpartisipasi aktiv dalam pelatihan secara daring. Sebagai rangkaian dalam pelatihan ini peserta kegiatan pelatihan manajemen bengkel diberikan soal pretes sebagai ukuran dari pengetahuan awal guru SKM dalam memahami dan menerapkan pengajaran dalam mata pelajaran praktik. Kemudian dari hasil pretes tersebut dilakukan perlakukan sesuai dengan kebutuhan yang diperlukan dalam meningkatkan pengetahuan dan pola metode pengajaran dalam melaksanakan manajemen bengkel/laboratorium di Sekolah Menengah Kejuruan. Dalam proses pelatihan pemateri memberikan gambaran dan metode terkait bagaimana manajemen bengkel/laboratorium yang dapat di terapkan dalam mata pelajaran praktik di SMK. Setelah pemberian materi selesai dilanjutkan pada tahap selanjutnya yaitu post test terhadap peserta kegiatan PKM Bidang Ilmu sebagai pengukuran hasil pencapaian selama proses kegiatan berlangsung.

Sebagai tindak lanjut dari tahapan sebelumnya, maka proses pendampingan pasca pelatihan terus diberikan hinga saat ini. Para peserta terus dipantau perkembangnnya dan tim PKM Bidang ilmu secara instensif memberikan layanan pendampingan dan bantuan teknis yang diperlukan oleh para peserta. Dalam perkembanganya positif karena perserta atau guru dalam pelatihan dapat mengembangkan dan menerapkan manajemen bengkel/laboratorium di SMK sesuai dengan kebutuhan mata pelajaran praktik yang terdapat di SMK. Adapun tahapan kegiatan selanjutnya adalah membuat model pembelajaran manajemen bengkel/laboratorium yang lebih khusus dalam setiap mata pelajaran praktik yang ada di berbagai jurusan yang terdapat di SMK agar setiap mata pelajaran praktik dapat memiliki niai efisiensi dan efektifitas guna menunjang pembelajaran praktik.

\section{KESIMPULAN DAN SARAN}

Berdasarkan hasil pelaksanaan Kegiatan Pengabdian kepada Masyarakat (PkM) Bidang Ilmu dalam pelatihan manajemen bengkel/laboratorium dalam mata pelajaran praktik di SMK maka diperoleh kesimpulan sebagai berikut:
1. Kegiatan Pengabdian kepada Masyarakat Bidang Ilmu dalam pelatihan manajemen bengkel/laboratorium dapat meningkatkan kualitas sumber daya tenaga pengajar di SMK terutama bagi guru mata pelajaran praktik, hal ini terlihat dari model dan metode pembelajaran praktik yang dengan baik dan dapat dikembangkan lebih lanjut dengan bekerjasama dengan pihak institusi pendidikan tinggi.

2. Model pelatihan dan dan pengembangan, Kegitan PKM ini dapat memberikan informasi dan transformasi pengetahuan guru mata pelajaran praktik di SMK mengenai manajemen bengkel/laboratorium pada mata pealajaran praktik dan aplikasinya yang dapat dimanfaatkan sebagai sarana model dan metode pembelajaran yang berguna di Sekolah Menengah Kejuruan.

3. Model pelatihan manajemen bengkel/laboratorium pada mata pelajaran praktik di SMK yang telah disusun didasarkan kepada kebutuhan Sekolah Menengah Kejuruan, observasi lapangan, hasil studi komparasi yang telah mengembangkan dan mengaplikasikan berbagai model dan metode pembelajaran pada mata pelajaran praktikum yang tedapat di SMK.

\section{REFERENSI}

Finch, C.R. dan Crunkilton, J.R. 1984. Curriculum Development In Vocational and Technical Education. London: Allyn and Bacon, Inc.

Singh, U.K \& Sudarshan, K.N. 2015. Vocational Education. New Delhi (India): Discovery Publishing House PVT. LTD.

Miller, Melvin D. 1985. Principles and a Philosophy for Vocational Education. Coloumbus: The Ohio State University.

Billett, Stehen. 2011. Vocational Education (Purposes, Trsditions and Prospects). Griffith University, QLD, Australia: Springer.

Rivai, Veithzal dan Sagala, Jauvani E. 2010. Manajemen Sumber Daya Manusia untuk Perusahaan. Jakarta: Rajagrafindo Persada.

Iik Nurulpaik, Hasbullah, Wawan Purmana, Neris Peri Ardiansyah

Jurnal Ilmiah Teknologi Informasi Terapan

Volume 7, No 1, 15 Desember 2020 
Yoto. 2015. Manajemen Bengkel Teknik Mesin. Malang: Aditya Media Publishing.

Terry, G.R. 1974. Principle of management (6thed.). Homewood: Richard D. Irwin

Aurigemma, J., et.al, 2013. Turning experiments objects: the cognitive processes involved in the design of a labon- a-chip device. Journal of Engineering Education, 102, 117-140

Rochadi, L.H. 2011. Pengelolaan workshop praktek jurusan bangunan di SMK yang efektif dan efisien menuju standar bengkel di industri. Makalah disajikan dalam Workshop Pengelolaan Bengkel SMK Jawa Tengah Tahun 2011, di Semarang. 